Marquette University

e-Publications@Marquette

$12-1-2017$

\title{
Factors That Influence Self-Reported Health Changes With Caregiving
}

Margaret Danilovich

Northwestern University

Xiaoling Xiang

Northwestern University

Daniel Pinto

Marquette University, daniel.pinto@marquette.edu

Published version. Journal of Aging and Health, Vol. 29, No. 8 (December 1, 2017): 1444-1458. DOI. (C) 2018 by SAGE Publications. Used with permission.

Daniel Pinto was affiliated with Northwestern University at the time of publication. 
Marquette University

\section{e-Publications@Marquette}

\section{Physical Therapy Faculty Research and Publications/College of Health Sciences}

This paper is NOT THE PUBLISHED VERSION; but the author's final, peer-reviewed manuscript. The published version may be accessed by following the link in the citation below.

Journal of Aging and Health, Vol. 29, No. 8 (December, 2017): 1444-1458. DOI. This article is (C) SAGE Publications and permission has been granted for this version to appear in e-Publications@Marquette. SAGE Publications does not grant permission for this article to be further copied/distributed or hosted elsewhere without the express permission from SAGE Publications.

\section{Contents}

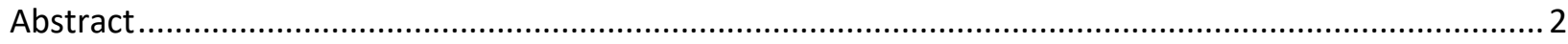

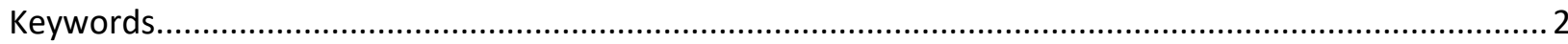

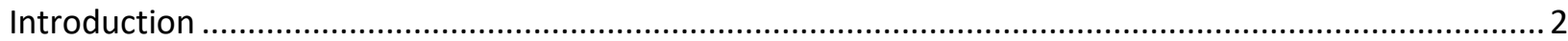

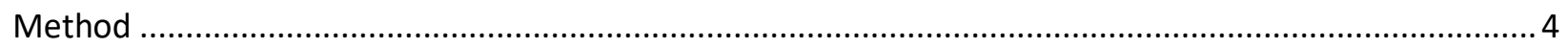

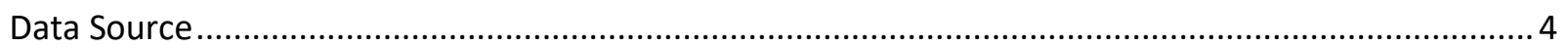

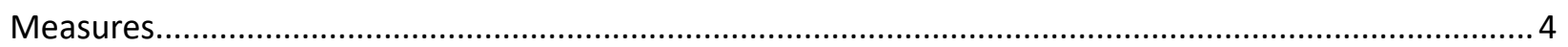

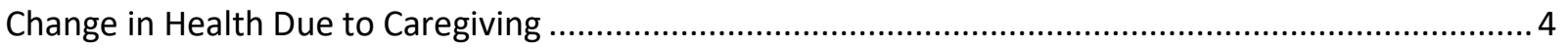

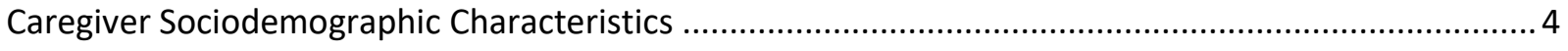

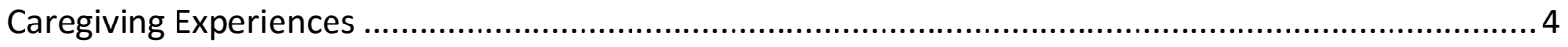

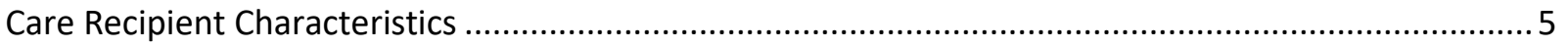

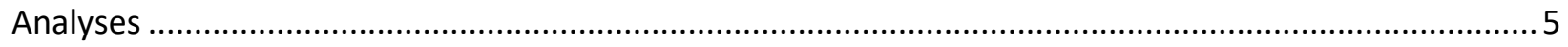

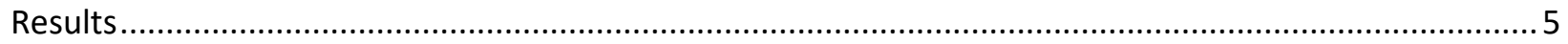

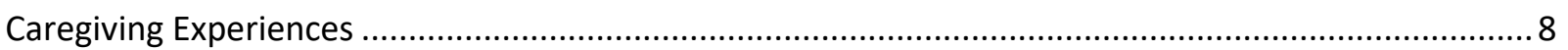

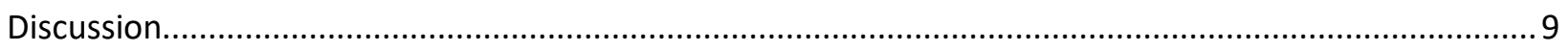

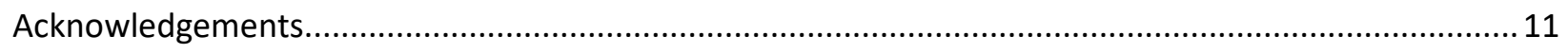

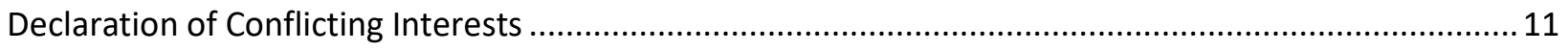

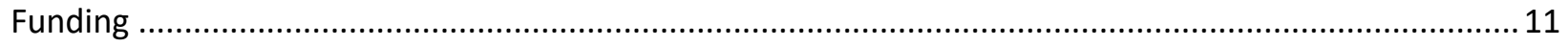




\title{
Factors That Influence Self-Reported Health Changes with Caregiving
}

\author{
Margaret Danilovich \\ Northwestern University, Chicago, IL \\ Xiaoling Xiang \\ Northwestern University, Chicago, IL \\ Daniel Pinto \\ Northwestern University, Chicago, IL
}

\section{Abstract}

Objective: This study examined factors associated with the self-reported change in health status as a result of caregiving. Method: Multinomial logistic regression were performed to examine the sociodemographic characteristics, care recipients' characteristics, and caregiving experiences that affect caregivers' perceptions of health affected by caregiving using data from 1,087 caregiver respondents in the Caregiving in the U.S. 2015 data set. Data were collected through an online or telephone survey of randomly selected adults in 50 states. Results: Worsened self-reported health with caregiving occurred for caregivers aged 50 to 64, racial/ethnic minorities, those who lived within 20 min of the care recipient's home, the presence of cognitive deficits, prolonged caregiving, and limited availability of accessible and affordable care services. Importantly, the feeling of choice in taking on care responsibilities was associated with an over fourfold increase in the odds ratio (OR) of better health in response to caregiving $(\mathrm{OR}=4.21$; confidence interval $[\mathrm{Cl}]=[1.95,9.08] ; p<.001)$. Discussion: Results suggest that improving accessibility of social service resources to assist caregivers in being better supported and having more choice in caregiving responsibilities may foster a positive change in health status with caregiving.

\section{Keywords}

caregiving, self-reported health informal caregiving

\section{Introduction}

A consequence of an aging society with strong preferences for aging-in-place is an increased reliance on informal caregiving services. Caregiving requires a tremendous amount of commitment on the part of the caregiver through emotional, physical, mental, and financial mechanisms. This commitment can 
contribute to high levels of stress leading to depression and anxiety (de Oliveira et al., 2014; Givens, Mezzacappa, Heeren, Yaffe, \& Fredman, 2014), impaired cardiovascular function (Torimoto-Sasai, Igarashi, Wada, Ogata, \& Yamamoto-Mitani, 2015), immune dysregulation (Lovell \& Wetherell, 2011), sleep disturbances (Peng, Lorenz, \& Chang, 2015), and lower quality of life (Berglund, Lytsy, \& Westerling, 2015; Thai, Barnhart, Cagle, \& Smith, 2015). However, not all caregivers exhibit these symptoms and some, in fact, show enhanced health outcomes compared with noncaregivers. A recent report found that $83 \%$ of caregivers believe that providing care has been a positive experience in their life (National Opinion Research Center, 2014). The Healthy Caregiver Hypothesis proposes that the demands of the caregiving role require increased levels of physical activity, as well as provide a cognitive stimulus to promote overall health improvements in response to caregiving (Fredman et al., 2008). Lower rates of mortality (Brown et al., 2009; Fredman, Doros, Ensrud, Hochberg, \& Cauley, 2009; O'Reilly, Connolly, Rosato, \& Patterson, 2008), decreased functional decline (Fredman et al., 2009), and improved cognitive outcomes (Bertrand et al., 2012) have been found for caregivers compared with agematched noncaregivers supporting this hypothesis.

Although both subjective and objective positive health outcomes have been reported in response to caregiving, an understanding of the factors that contribute to improved health with caregiving have not been fully elucidated. Individual factors, such as the successful utilization of coping skills, as well as interpersonal factors such as social support and the quality of the caregiving dyad relationship have been shown to contribute to a positive and rewarding caregiving experience (Koerner, Kenyon, \& Shirai, 2009). Although much research has focused on the comparison of health outcomes between caregivers and noncaregivers (Ahn, Hochhalter, Moudouni, Smith, \& Ory, 2012; Anderson et al., 2013; Bertrand et al., 2012; Fredman et al., 2009), little is known about the individual, interpersonal, and contextual factors that contribute to changes in caregiver health status with caregiving, and the limited research available has primarily found negative health changes in response to caregiving. For individuals following heart transplant, caregivers with poor initial physical health and weak coping styles experienced the most negative changes in health with caregiving (Dew et al., 1998). Worsened physical health with caregiving has also been associated with older, nonspousal caregivers, as well as those with less income and education, and those who live with the care recipient (Pinquart \& Sorensen, 2007).

The current study sought to examine the contribution of caregiver and care recipient characteristics and caregiving experiences on self-reported change in health status among caregivers providing care to an adult aged 50 years or older. We hypothesized that caregivers would be more likely to express a negative change in health status with prolonged caregiving, greater levels of caregiving burden, care for a person with functional or cognitive deficits, and less accessibility to caregiving support. We add to the literature on this topic by (a) using a large, recently available nationally representative data set for caregivers for adults more than 50 years of age; (b) providing information regarding the circumstances under which caregiving contributes to a change in self-reported overall health; and (c) offering an analysis of the profile of caregivers who experience negative or positive health changes in response to caregiving. 


\section{Method}

\section{Data Source}

Data for this study were from the Caregiving in the U.S. 2015 Public Use Data File. The Caregiving in the U.S. 2015 data set is a joint research study between American Association of Retired Persons (AARP) and the National Alliance for Caregiving to examine the experiences and challenges of unpaid family caregivers in the United States. Conducted in late 2014, the Caregiving in the U.S. 2015 Data File drew respondents from the GfK KnowledgePane ${ }^{\circledR}{ }^{\circledR}$, a probability-based, web-enabled panel to complete webbased surveys in exchange for free Internet access or other compensation. KnowledgePanel ${ }^{\circledR}$ uses a dual frame sampling including address-based sampling and a national random-digit dial sample frame to recruit a nationally representative sample of respondents. Screening interviews were conducted online with 7,600 participants and full online interviews were conducted only with eligible caregivers aged 18 years or older who provided unpaid care to an adult. A total of 1,248 eligible caregivers of adults completed full online interviews. We restricted our study sample to the 1,087 caregivers of recipients 50 years or older that completed full online interviews. We excluded caregivers of recipients younger than 50 years old to focus on caregivers of older adults.

\section{Measures}

\section{Change in Health Due to Caregiving}

Respondents were asked, "How would you say caregiving affected your health?" with valid answers being "made it better," "not affected," or "made it worse." Responses of "not sure" or "refused" were coded as missing and excluded from final analysis $(n=3)$. We used the response "not affected" as the reference group in logistic regression analysis.

\section{Caregiver Sociodemographic Characteristics}

We examined caregiver characteristics including age, sex (male or female), race/ethnicity (non-Hispanic White, non-Hispanic African American, Hispanic, and Other), marital status (married or living with a partner, widowed/separated/divorced, and never married), education (less than high school, high school graduate or equivalent, technical school or some college, college graduate or higher), and a dichotomous indicator of being employed while providing informal caregiving services at any point in past year.

\section{Caregiving Experiences}

Caregivers reported on their experiences in terms of length of caregiving time, assistance provided, availability and access of supportive resources, and choice of assuming care responsibilities. Caregivers were asked how long they had been providing care to the recipient and responses were coded into five categories including "less than 6 months," "6 months to 1 year," "1 to 4 years," " 5 to 9 years," and "10 years or more." Caregivers rated caregiving burden on a 5-point Likert-type scale with higher scores indicating greater amounts of burden. Moreover, caregivers were asked whether they provided help with activities of daily living (ADLs) including transfers, dressing, toileting, bathing, continence, and eating. A single score of the number of ADLs caregivers provided help with was created and included in the final analysis. In addition, caregivers rated their difficulty in accessing affordable care services in their recipients' local area on a 5-point Likert-type scale with higher scores associated with greater difficulty. A dichotomous indicator of the use of respite services was also included in the analysis. 
Finally, caregivers were asked if they felt that they "had a choice in taking on care for recipient" and the responses were "yes" or "no."

\section{Care Recipient Characteristics}

The following characteristics of care recipients were included in the analysis: age; sex (male or female); a dichotomous indicator of living in a rural area; a dichotomous indicator of having Alzheimer's, dementia, or mental confusion; and living arrangements in relation to their caregivers (in the caregiver's household, within $20 \mathrm{~min}$ of the caregiver's home, within 20 to $60 \mathrm{~min}$ of the caregiver's home, 1 to $2 \mathrm{hr}$ away from the caregiver's home, and more than $2 \mathrm{hr}$ away from the caregiver's home).

\section{Analyses}

We used univariate analysis to provide a description of the sample. We conducted multinomial logistic regression to examine the extent to which caregivers' sociodemographic characteristics, care recipients' characteristics, and caregiving experiences affected caregivers' perceptions of change in health due to caregiving. Multinomial logistic regression is used to model an outcome that is measured on a nominal scale with more than two levels. Survey sampling weights were incorporated in all analyses to provide nationally representative estimates. Statistical analyses were conducted using Stata $12.1 \mathrm{SE}$ version (StataCorp, College Station, TX).

\section{Results}

Table 1 presents descriptive statistics of the study sample. Caregivers of older adults were on average 50 years old. The majority of the 1,087 caregivers of older adults were female (60\%), non-Hispanic White $(62 \%)$, married or living with a partner (65\%), had at least a high school education (93\%), and were concurrently engaged in paid employment in addition to caregiving (59\%). Care recipients were on average 75 years of age, predominantly female (67\%), and lived with their caregiver or within a 20 min radius $(75 \%)$. The majority of caregivers $(76 \%)$ had provided care for 4 years or less, were providing an average assistance with $1.7 \mathrm{ADLs}$, and gave a neutral rating of caregiving burden (2.9 on 5-point Likerttype scale). The feeling of choice in taking on care for the care recipient was equally divided with $50 \%$ of caregivers reporting the sense of choice. The majority of caregivers felt that caregiving did not change their health (73.3\%); however, $21.3 \%$ perceived a decrease in their own health as a result of caregiving. 
Table I. Characteristics of Caregivers Providing Care to an Adult Aged 50 or $\operatorname{Older}(N=1,087)$

\begin{tabular}{|c|c|c|}
\hline & $\begin{array}{l}\text { Unweighted } \\
\text { number }\end{array}$ & $\begin{array}{l}\text { Weighted } \\
\text { estimates }\end{array}$ \\
\hline \multicolumn{3}{|l|}{ Caregiver sociodemographic characteristics } \\
\hline Age in years $(M, S D)$ & - & $50.3(16.2)$ \\
\hline Male $(\%)$ & 440 & 40.2 \\
\hline \multicolumn{3}{|l|}{ Race/ethnicity (\%) } \\
\hline White, non-Hispanic & 613 & 62.2 \\
\hline African American, non-Hispanic & 178 & 13.0 \\
\hline Hispanic & 175 & 16.1 \\
\hline Other & 121 & 8.7 \\
\hline \multicolumn{3}{|l|}{ Marital status (\%) } \\
\hline Married or living with a partner & 702 & 64.9 \\
\hline Widowed, separated, or divorced & 175 & 15.3 \\
\hline Never married & 190 & 19.9 \\
\hline \multicolumn{3}{|l|}{ Education (\%) } \\
\hline Less than high school & 78 & 7.2 \\
\hline High school graduate or equivalent & 307 & 28.3 \\
\hline Technical school or some college & 297 & 28.5 \\
\hline College graduate or higher & 405 & 36.0 \\
\hline $\begin{array}{l}\text { Employed while caregiving at any point in } \\
\text { past year (\%) }\end{array}$ & 621 & 59.0 \\
\hline \multicolumn{3}{|l|}{ Care recipient characteristics } \\
\hline Age in years $(M, S D)$ & - & $74.7(12.2)$ \\
\hline Male $(\%)$ & 348 & 32.9 \\
\hline Live in a rural area $(\%)$ & 291 & 28.3 \\
\hline \multicolumn{3}{|l|}{ Living arrangements (\%) } \\
\hline In caregiver's household & 348 & 32.3 \\
\hline Within 20 min of caregiver's home & 454 & 42.6 \\
\hline Within 20-60 min of caregiver's home & 146 & 13.1 \\
\hline $\mathrm{I}-2 \mathrm{hr}$ away from caregiver's home & 46 & 4.4 \\
\hline More than $2 \mathrm{hr}$ away from caregiver's home & 84 & 7.7 \\
\hline Has Alzheimer's, dementia, or mental confusion (\%) & 267 & 24.0 \\
\hline \multicolumn{3}{|l|}{ Caregiving experiences } \\
\hline \multicolumn{3}{|l|}{ Length of time provided care (\%) } \\
\hline Less than 6 months & 284 & 27.7 \\
\hline 6 months to I year & 219 & 19.6 \\
\hline I-4 years & 317 & 28.7 \\
\hline $5-9$ years & 139 & 13.0 \\
\hline 10 years or more & 127 & 11.0 \\
\hline Rating of caregiving burden $(M, S D)$ & - & $2.9(1.4)$ \\
\hline Number of help with ADLs performed $(M, S D)$ & - & $1.7(1.9)$ \\
\hline $\begin{array}{l}\text { Ratings of difficulty in getting affordable care } \\
\text { services in recipient's local area }(M, S D)\end{array}$ & - & $2.7(1.2)$ \\
\hline Ever used respite services (\%) & 183 & 15.7 \\
\hline $\begin{array}{l}\text { Feel like had a choice in taking on care for } \\
\text { recipient (\%) }\end{array}$ & 542 & 50.5 \\
\hline \multicolumn{3}{|l|}{ Perceptions of change in health due to caregiving (\%) } \\
\hline Not affected & 799 & 73.3 \\
\hline Made it better & 52 & 5.4 \\
\hline Made it worse & 233 & 21.3 \\
\hline
\end{tabular}

Note. ADLs = activities of daily living.

Table 2 presents results from multinomial logistic regression on predictors of perceived change in health due to caregiving. Caregivers aged 50 to 64 years compared with caregivers aged 18 to 49 (relative risk ratio $[R R R]=1.65,95 \%$ confidence interval $[\mathrm{Cl}]=[1.07,2.53]$ ) were more likely to report that caregiving made their health worse. Caregivers who were African American ( $R R R=0.47,95 \% \mathrm{Cl}=[0.27,0.80]$ ) or 
Hispanic ( $R R R=0.55,95 \% \mathrm{Cl}=[0.32,0.95])$ as compared with non-Hispanic White, and caregivers with some college education as compared with less than high school education, were less likely to report that caregiving made health better $(\mathrm{RRR}=0.32,95 \% \mathrm{Cl}=[0.11,0.96]$ for technical school or some college and $\mathrm{RRR}=0.25,95 \% \mathrm{Cl}=[0.08,0.80]$ for college education or higher). 
Table 2. Results From Multinomial Logistic Regression on Correlates of Caregiver's Perceptions of Change in Health Due to Caregiving.

\begin{tabular}{|c|c|c|c|c|}
\hline & \multicolumn{2}{|c|}{$\begin{array}{l}\text { Caregiving made health worse } \\
\qquad(n=233)\end{array}$} & \multicolumn{2}{|c|}{$\begin{array}{l}\text { Caregiving made health better } \\
\qquad(n=52)\end{array}$} \\
\hline & Relative risk ratio $(95 \% \mathrm{Cl})$ & $p$ & Relative risk ratio $(95 \% \mathrm{Cl})$ & $p$ \\
\hline \multicolumn{5}{|l|}{ Caregiver sociodemographic characteristics } \\
\hline \multicolumn{5}{|l|}{ Age group } \\
\hline $18-49$ years & Reference & & Reference & \\
\hline $50-64$ years & $1.65[1.07,2.53]$ & .023 & $0.45[0.20,1.05]$ & .064 \\
\hline 65 and above & $0.87[0.50,1.5 I]$ & .616 & $0.83[0.32,2.19]$ & .713 \\
\hline Male & $0.71[0.50,1.01]$ & .057 & $0.65[0.33,1.26]$ & .202 \\
\hline \multicolumn{5}{|l|}{ Race/ethnicity } \\
\hline White, non-Hispanic & Reference & & Reference & \\
\hline African American & $0.47[0.27,0.80]$ & .005 & $1.97[0.81,4.77]$ & .132 \\
\hline Hispanic & $0.55[0.32,0.95]$ & .033 & $1.18[0.49,2.84]$ & .712 \\
\hline Other & $0.59[0.32,1.10]$ & .095 & $1.74[0.64,4.75]$ & .279 \\
\hline \multicolumn{5}{|l|}{ Marital status } \\
\hline Married or living with a partner & Reference & & Reference & \\
\hline Widowed, separated, or divorced & $0.65[0.39,1.09]$ & .102 & $1.96[0.88,4.35]$ & .100 \\
\hline Never married & $1.00[0.62,1.62]$ & .997 & $1.62[0.72,3.62]$ & .241 \\
\hline \multicolumn{5}{|l|}{ Education } \\
\hline Less than high school & Reference & & Reference & \\
\hline High school graduate or equivalent & $1.41[0.63,3.16]$ & .398 & $0.47[0.17,1.30]$ & .147 \\
\hline Technical school or some college & $1.58[0.70,3.58]$ & .275 & $0.32[0.11,0.96]$ & .042 \\
\hline College graduate or higher & $1.49[0.65,3.40]$ & .342 & $0.25[0.08,0.80]$ & .019 \\
\hline Employed while caregiving at any point in past year & $0.74[0.51,1.08]$ & .123 & $2.02[0.95,4.30]$ & .067 \\
\hline \multicolumn{5}{|l|}{ Care recipient characteristics } \\
\hline Age by 5 -year interval & $0.93[0.86,1.00]$ & .066 & $1.03[0.89,1.18]$ & .694 \\
\hline Male & $0.98[0.68,1.4 \mathrm{I}]$ & .906 & $1.4 \mid[0.74,2.67]$ & .296 \\
\hline Live in a rural area & $1.22[0.83,1.80]$ & .321 & $2.84[1.45,5.56]$ & .002 \\
\hline \multicolumn{5}{|l|}{ Living arrangements } \\
\hline In caregiver's household & Reference & & Reference & \\
\hline Within 20 min of caregiver's home & $0.52[0.33,0.82]$ & .005 & $0.26[0.11,0.61]$ & .002 \\
\hline Within 20-60 min of caregiver's home & $0.55[0.29,1.03]$ & .060 & $0.68[0.26,1.83]$ & .448 \\
\hline I-2 hr away from caregiver's home & $0.61[0.25,1.47]$ & .268 & $0.49[0.09,2.57]$ & .398 \\
\hline More than $2 \mathrm{hr}$ away from caregiver's home & $0.81[0.40,1.61]$ & .543 & $0.53[0.14,2.02]$ & .352 \\
\hline Has Alzheimer's, dementia, or mental confusion & $2.04[1.39,3.00]$ & $<.001$ & $0.83[0.36,1.87]$ & .647 \\
\hline \multicolumn{5}{|l|}{ Caregiving experiences } \\
\hline \multicolumn{5}{|l|}{ Length of time provided care } \\
\hline Less than 6 months & Reference & & Reference & \\
\hline 6 months to I year & $1.20[0.66,2.17]$ & .547 & $1.19[0.46,3.08]$ & .722 \\
\hline I-4 years & $2.56[1.53,4.3 I]$ & $<.001$ & $1.78[0.77,4.10]$ & .175 \\
\hline $5-9$ years & $2.55[1.38,4.70]$ & .003 & $2.21[0.77,6.34]$ & .140 \\
\hline 10 years or more & $3.82[2.08,7.03]$ & $<.001$ & $0.93[0.23,3.72]$ & .916 \\
\hline Rating of caregiving burden & $1.08[0.88,1.32]$ & .469 & $1.07[0.75,1.51]$ & .708 \\
\hline Number of help with ADLs performed & $1.16[1.01,1.32]$ & .030 & $1.09[0.87,1.37]$ & .447 \\
\hline $\begin{array}{l}\text { Ratings of difficulty in getting affordable care } \\
\text { services in recipient's local area }\end{array}$ & $1.31[1.14,1.51]$ & $<.001$ & $1.17[0.90,1.51]$ & .236 \\
\hline Ever used respite services & $1.09[0.68,1.74]$ & .730 & $1.75[0.83,3.72]$ & .143 \\
\hline Feel like had a choice in taking on care for recipient & $0.41[0.28,0.59]$ & $<.001$ & $4.21[1.95,9.08]$ & $<.001$ \\
\hline
\end{tabular}

Note. Reference group for multinomial logistic regression was caregivers who reported that their health was "not affected" by caregiving. ADLs $=$ activities of daily living.

A number of care recipient characteristics were significantly associated with self-rated health changes in response to caregiving. Caregivers who provided care to a person with Alzheimer's, dementia, or mental confusion, were more likely to report that caregiving made their health worse $(R R R=2.04, \mathrm{Cl}=[1.39$, 3.00]). Caregivers whose care recipients resided within $20 \mathrm{~min}$ of the caregiver's home were less likely to report caregiving made their health worse or better compared with caregivers whose care recipients lived within the household ( $R R R=0.52,95 \% \mathrm{Cl}=[0.33,0.82])$. Caregivers whose care recipients lived in a rural area were more likely to report that caregiving made health better $(\mathrm{RRR}=2.85, \mathrm{Cl}=[1.45,5.56])$.

\section{Caregiving Experiences}

The length of time providing care was significantly associated with increased risk of worsened selfreported health as a result of caregiving. In particular, providing care for 10 or more years was 
associated with more than a threefold increase in relative risk of worsened self-reported health as a result of caregiving ( $R R R=3.82, \mathrm{Cl}=[2.08,7.03])$. Importantly, caregivers who reported a choice in taking on care responsibilities were 4 times as likely to report better health with caregiving compared with those caregivers who felt no choice in assuming care responsibilities (RRR $=4.21, \mathrm{Cl}=[1.95,9.08]$ ).

\section{Discussion}

This article is the first, to our knowledge, to examine the self-reported change in overall health as a result of caregiving using the Caregiving in the U.S. 2015 data. Results show that choice in assuming care responsibilities, length of time providing informal caregiving services, care recipient ADL impairment and cognitive deficits, accessibility of caregiving resources, and living arrangement are key contributory factors to a change in self-reported overall health with caregiving. Importantly, choice in taking on care responsibilities had the strongest relationship with a positive change in health as a result of caregiving.

A recent meta-analysis found that physical health among caregivers providing care for individuals with stroke remained stable over time (Salter, 2010). Our work goes beyond the disease-specific focus to investigate changes in self-reported overall health among caregivers providing care to older adults with various health conditions. Although an understanding of the disease-specific impact on caregiving is important, especially in progressive diseases such as dementia, the majority of older adults have multiple chronic conditions and subsequent ADL impairment (Gerteis et al., 2014). Thus, an understanding of the impact of caring for an individual with a focus on ADL impairment regardless of specific chronic condition is of importance in an aging society. Our study is also unique in focusing on overall general self-reported health without distinguishing between physical and mental health. Although worsened physical health outcomes have been found for older adult caregivers (Pinquart \& Sorensen, 2007), our findings contrasted by showing that middle-aged caregivers 50 to 64 years old were the most likely age group to report worse health with caregiving.

Consistent with prior research documenting a positive association between health outcomes and resources (Ahn et al., 2012; Rabow, Hauser, \& Adams, 2004), the current study found that limited access to resources is associated with a negative change in self-reported health with caregiving. Although the difficulty in accessing affordable care resources was associated with worsened self-reported health, the use of respite services was not associated with either negative or positive health changes for caregivers. It may be that respite services are used in terminal caregiving, at which point, the use of this support service is not able to combat the effects of the chronicity of caregiving. We believe these results advocate that caregivers likely desire and need support resources outside of respite and the timing and preferences for these specific needs warrant further investigation. In the light of an aging society with less availability of informal caregivers (Super, 2002), affordable resources to support existing informal caregivers throughout the entire caregiving process, as well as cost-effective formal caregiving services will need to be developed and made accessible.

Choice in assuming the caregiver role was strongly associated with a positive change in health with caregiving. Choice in caregiving is often influenced by social or economic pressures. Our findings are congruent with other work showing that caregivers have better physical health outcomes with increased preparedness for future financial needs (Ahn et al., 2012). Financial preparedness is likely to offset the economic pressures of caregiving, promoting better outcomes. Our results are also aligned with findings that caregivers without a choice in assuming responsibilities were 3 times as likely to report burden 
compared with caregivers who had a choice (Winter, Bouldin, \& Andreseni, 2010). Further research is needed to elucidate the specific components of choice such as opportunity costs, financial pressures, and social pressures to develop strategies to assist caregivers in effectively coping, as well as proactively plan for future needs so that caregiving responsibilities are not thrust upon an individual. Providing coping resources to help caregivers feel a decreased sense of obligation may reduce the negative health consequences and this relationship merits further study.

Interesting, the rating of caregiving burden was not associated with a positive or negative change in overall self-reported health as a result of caregiving. Average reports of burden were 2.9 on a 5-point Likert-type scale indicating that most caregivers felt a neutral degree of caregiver burden. It may be that the limited scale options used in the initial data collection did not allow caregivers to express the full range of burden symptoms, thus limiting our inference of the relationship between burden and selfreported health change.

Rural and urban environments pose unique challenges to the caregiving experience. Our findings are interesting in light of other work that notes reduced availability of formal supports in rural geographic areas (Bedard, Koivuranta, \& Stuckey, 2004) which should theoretically increase strain and negatively affect health outcomes. However, other research has documented that informal caregivers in urban areas report greater social isolation and difficulties in obtaining informal assistance (Ehrlich, Boström, Mazaheri, Heikkilä, \& Emami, 2015). The complexities of environment, resource acquisition, and social isolation on the caregiving experience merit further research attention.

The results of this study are not without limitations. The cross-sectional nature of the survey methodology does not allow for examination of prospective change over time, limiting our ability to draw conclusions about causality. Furthermore, all data in this survey were self-reported by the caregiver, limiting the perspective of health changes. It may be that caregivers do not notice or deny the impact of caregiving on their health, whereas other parties such as a spouse or medical professional would more accurately and readily note changes in health.

Despite these limitations, this study has important implications for policy makers in aging and future research. Our findings show that caregivers who report positive health changes in response to caregiving are more likely to be residing in a rural environment, living within $20 \mathrm{~min}$ of the care recipient's home, and feel a choice in assuming caregiving responsibilities. Caregivers reporting negative health changes in response to caregiving are more likely to be 50 to 64 years of age, Caucasian, have higher level of education, caring for someone with a cognitive or physical deficit, providing care for an increased length of time, and have difficulty accessing affordable care services. Identification of this profile associated with negative self-reported health changes due to caregiving is an initial step toward the development of a risk profile by which social services and supportive resources can be proactively directed toward caregivers of these characteristics.

For policy makers in aging, this research suggests a substantial need to improve accessibility of affordable care services to support caregivers and the care recipient. For researchers, this study points to the concept of choice in accepting caregiver responsibilities and the need for proactive service planning as an intervention that requires further development and implementation on a larger scale. Mechanisms to help older adults better plan for their future caregiving needs should be developed and tested to reduce the strain of forced caregiving situations. These efforts may reduce the negative 
change in self-reported health status for caregivers that would enable them to maintain a positive and effective caregiving environment for their care recipient.

\section{Acknowledgements}

The authors appreciate the generosity of the National Alliance for Caregiving and the American Association of Retired Persons in allowing us to use their data, published in 2010. The data from the NAC and AARP's National Caregiver survey are available in electronic form to nonprofit research organizations and individuals and deidentifiable for public use at no charge.

\section{Declaration of Conflicting Interests}

The authors declared no potential conflicts of interest with respect to the research, authorship, and/or publication of this article.

\section{Funding}

The authors disclosed receipt of the following financial support for the research, authorship, and/or publication of this article: The author (X.X.) was supported by a training grant from the National Institute on Disability, Independent Living, and Rehabilitation Research (NIDILRR), located in the Administration for Community Living (ACL) in the U.S. Department of Health and Human Services, Grant H133P130013 (Principal Investigator: Allen Heinemann, PhD).

\section{References}

Anderson, L. A., Edwards, V. J., Pearson, W. S., Talley, R. C., McGuire, L. C., Andresen, E. M. (2013). Adult caregivers in the United States: Characteristics and differences in well-being, by caregiver age and caregiving status. Preventing Chronic Disease, 10, E135.

Bedard, M., Koivuranta, A., Stuckey, A. (2004). Health impact on caregivers of providing informal care to a cognitively impaired older adult: Rural versus urban settings. Canadian Journal of Rural Medicine, 9, 15-23.

Berglund, E., Lytsy, P., Westerling, R. (2015). Health and wellbeing in informal caregivers and noncaregivers: A comparative cross-sectional study of the Swedish general population. Health and Quality of Life Outcomes, 13, Article 109.

Bertrand, R. M., Saczynski, J. S., Mezzacappa, C., Hulse, M., Ensrud, K., Fredman, L. (2012). Caregiving and cognitive function in older women: Evidence for the healthy caregiver hypothesis. Journal of Aging and Health, 24, 48-66.

Brown, S. L., Smith, D. M., Schulz, R., Kabeto, M. U., Ubel, P. A., Poulin, M., . . Langa, K. M. (2009). Caregiving behavior is associated with decreased mortality risk. Psychological Science, 20, 488494.

de Oliveira, G. R., Neto, J. F., de Camargo, S. M., Lucchetti, A. L., Espinha, D. C, Lucchetti, G. (2014). Caregiving across the lifespan: Comparing caregiver burden, mental health, and quality of life. Psychogeriatrics, 15, 123-132.

Dew, M. A., Goycoolea, J. M., Stukas, A. A., Switzer, G. E., Simmons, R. G., Roth, L. H., . . DiMartini, A. (1998). Temporal profiles of physical health in family members of heart transplant recipients: Predictors of health change during caregiving. Health Psychology, 17, 138-151. 
Ehrlich, K., Boström, A. M., Mazaheri, M., Heikkilä, K., Emami, A. (2015). Family caregivers' assessments of caring for a relative with dementia: A comparison of urban and rural areas. International Journal of Older People Nursing, 10, 27-37.

Fredman, L., Cauley, J. A., Satterfield, S., Simonsick, E., Spencer, S. M., Ayonayon, H. N. . . Health ABC Study Group . (2008). Caregiving, mortality, and mobility decline: The Health, Aging, and Body Composition (Health ABC) Study. Archives of Internal Medicine, 168, 2154-2162.

Fredman, L., Doros, G., Ensrud, K. E., Hochberg, M. C., Cauley, J. A. (2009). Caregiving intensity and change in physical functioning over a 2-year period: Results of the caregiver-study of osteoporotic fractures. American Journal of Epidemiology, 170, 203-210.

Gerteis, J., Izrael, D., Deitz, D., LeRoy, L., Ricciardi, R., Miller, T., Basu, J. (2014). Multiple chronic conditions chartbook (AHRQ Publications No. Q14-0038). Rockville, MD: Agency for Healthcare Research and Quality.

Givens, J., Mezzacappa, C., Heeren, T., Yaffe, K., Fredman, L. (2014). Depressive symptoms among dementia caregivers: role of mediating factors. American Journal of Geriatric Psychiatry, 22, 481488.

Koerner, S. S., Kenyon, D. B., Shirai, Y. (2009). Caregiving for elder relatives: Which caregivers experience personal benefits/gains? Archives of Gerontology and Geriatrics, 48, 238-245.

Lovell, B., Wetherell, M. A. (2011). The cost of caregiving: Endocrine and immune implications in elderly and non elderly caregivers. Neuroscience \& Biobehavioral Reviews, 35, 1342-1352.

National Opinion Research Center . (2014, May). Long term care in America: Expectations and realities. Retrieved from http://www.longtermcarepoll.org/PDFs/LTC\%202014/AP-NORC-LongTerm\%20Care\%20in\%20America_FINAL\%20WEB.pdf

O’Reilly, D., Connolly, S., Rosato, M., Patterson, C. (2008). Is caring associated with an increased risk of mortality? A longitudinal study. Social Science \& Medicine, 67, 1282-1290.

Peng, H.-L., Lorenz, R. A., Chang, Y.-P. (2015). Sleep quality in family caregivers of individuals with dementia: A concept analysis. Clinical Nursing Research, 24(5), 1-17.

Pinquart, M., Sorensen, S. (2007). Correlates of physical health of informal caregivers: A meta-analysis. The Journals of Gerontology. Series B, Psychological Sciences and Social Sciences, 62, P126-P137.

Rabow, M. W., Hauser, J. M., Adams, J. (2004). Supporting family caregivers at the end of life: "They don't know what they don't know." The Journal of the American Medical Association, 291, 483491.

Salter, K., Zettler, L., Foley, N., Teasell, R. (2010). Impact of caring for individuals with stroke on perceived health of informal caregivers. Disability Rehabilitation, 32, 273-281.

Super, N. (2002, January 23). Who will be there to care? The growing gap between caregiver supply and demand (NHPF background paper). Washington, DC: National Health Policy Forum.

Thai, J. N., Barnhart, C. E., Cagle, J., Smith, A. K. (2015). "It just consumes your life": Quality of life for informal caregivers of diverse older adults with late-life disability. American Journal of Hospice \& Palliative Care, 33, 644-650.

Torimoto-Sasai, Y., Igarashi, A., Wada, T., Ogata, Y., Yamamoto-Mitani, N. (2015). Female family caregivers face a higher risk of hypertension and lowered estimated glomerular filtration rates: A cross-sectional, comparative study. BMC Public Health, 15, Article 177.

Winter, K. H., Bouldin, E. D., Andresen, E. M. (2010). Lack of choice in caregiving decision and caregiver risk of stress, North Carolina, 2005. Preventing Chronic Disease, 7, A41. 
